\title{
Comparison of the Inhibitory and Excitatory Effects of ADHD Medications Methylphenidate and Atomoxetine on Motor Cortex
}

\author{
Donald L Gilbert*,', Keith R Ridel ${ }^{2}$, Floyd R Sallee ${ }^{3}$, Jie Zhang', Tara D Lipps' and Eric M Wassermann ${ }^{4}$ \\ 'Division of Neurology, Cincinnati Children's Hospital Medical Center, University of Cincinnati, Cincinnati, OH, USA; ${ }^{2}$ University of Cincinnati \\ School of Medicine, Cincinnati, OH, USA; ${ }^{3}$ Division of Psychiatry, University of Cincinnati, Cincinnati, OH, USA; ${ }^{4}$ Brain Stimulation Unit, \\ National Institute of Neurological Disorders and Stroke, Bethesda, MD, USA
}

\begin{abstract}
Stimulant and norepinephrine (NE) reuptake inhibitor medications have different effects at the neuronal level, but both reduce symptoms of attention deficit hyperactivity disorder (ADHD). To understand their common physiologic effects and thereby gain insight into the neurobiology of ADHD treatment, we compared the effects of the stimulant methylphenidate (MPH) and NE uptake inhibitor atomoxetine (ATX) on inhibitory and excitatory processes in human cortex. Nine healthy, right-handed adults were given a single, oral dose of $30 \mathrm{mg} \mathrm{MPH}$ and $60 \mathrm{mg}$ ATX at visits separated by I week in a randomized, double-blind crossover trial. We used paired and single transcranial magnetic stimulation (TMS) of motor cortex to measure conditioned and unconditioned motor-evoked potential amplitudes at inhibitory $(3 \mathrm{~ms})$ and facilitatory $(10 \mathrm{~ms})$ interstimulus intervals (ISI) before and after drug administration. Data were analyzed with repeated measures, mixed model regression. We also analyzed our findings and the published literature with meta-analysis software to estimate treatment effects of stimulants and NE reuptake inhibitors on these TMS measures. There were no significant pretreatment differences or effects of treatment order. Both agents produced a significant increase in facilitation and a decrease in inhibition. Effects of ATX and MPH did not differ significantly. Pooled estimates from published studies show similar results for stimulants and NE reuptake inhibitors. In conclusion, in healthy adults, both stimulant and nonstimulant medications for ADHD decrease cortical inhibition and increase cortical facilitation. Cortical inhibition, shown previously to be abnormal in ADHD, may play a key role producing behavioral pathology.

Neuropsychopharmacology (2006) 31, 442-449. doi:I 0. I038/sj.npp. I 300806; published online 20 July 2005
\end{abstract}

Keywords: attention deficit hyperactivity disorder; neurophysiology; transcranial magnetic stimulation; methylphenidate; atomoxetine; catecholamine

\section{INTRODUCTION}

There are substantial differences in the mechanisms of the stimulant and nonstimulant medications used to treat attention deficit hyperactivity disorder (ADHD). Stimulants like methylphenidate (MPH) act as indirect dopamine (DA) agonists, inhibiting DA reuptake via occupation of the DA transporter (Volkow et al, 1998). MPH increases DA in striatum, and both norepinephrine (NE) and DA in prefrontal cortex (Bymaster et al, 2002). Atomoxetine (ATX), a nonstimulant, selective NE reuptake inhibitor (Zerbe et al, 1985) recently approved in the United States

\footnotetext{
*Correspondence: Dr DL Gilbert, Division of Neurology, Cincinnati Children's Hospital Medical Center, ML \#2015, 3333 Burnet Avenue Cincinnati, OH 45229-3039, USA, Tel: + I 513636 4222, Fax: + I 5 I 3636 3980, E-mail: d.gilbert@cchmc.org

Received I 8 March 2005; revised II May 2005; accepted I 8 May 2005 Online publication: 25 May 2005 at http://www.acnp.org/citations/ Npp052505050 89/default.pdf
}

for treatment of ADHD, does not increase DA in striatum but, like MPH, increases both NE and DA in prefrontal cortex (Bymaster et al, 2002). Taken together, the clinical observation that both classes of drugs reduce ADHD symptoms and the experimental observation that both also alter DA and NE transmission in cerebral cortex suggest that these drugs affect a common cortical substrate of ADHD symptoms. Understanding why drugs which act differently on neurotransmitter systems produce similar therapeutic effects may yield insight into the neurobiology of ADHD and identify common, important markers of treatment effects.

The objective of this study was a direct comparison, with transcranial magnetic stimulation (TMS), of the cortical effects of two medications used to treat ADHD, a stimulant (MPH) and a nonstimulant (ATX). TMS has been used to study cortical changes in ADHD (Buchmann et al, 2003; Gilbert et al, 2004a; Moll et al, 2001; Ucles et al, 1996) and is sensitive to the effects of many drugs (Daskalakis 
et al, 2002; Ziemann 2004), including those affecting monoaminergic systems. TMS is a noninvasive, welltolerated (Garvey et al, 2001), safe (Gilbert et al, 2004b), and easily replicated (Gilbert et al, 2005) procedure for studying the physiological state of neural circuits in the human motor cortex. TMS of motor cortex produces a muscle twitch and a compound motor action potential or 'motor evoked potential' (MEP) that can be recorded from muscles and measured. Spinal cord recordings show that MEP amplitude depends on the size and number of the synchronous volleys of action potentials produced in the corticospinal neurons by the stimulus (Nakamura et al, 1997). The volleys reflect synaptically mediated recruitment and repeated firing of corticospinal neurons (Patton and Amassian 1954) produced by activation of intrinsic motor cortex circuits (Cracco et al, 1999). Thus, the amplitude of the TMS-evoked MEP is a quantitative measure of the state of neurons and synapses in the motor cortex.

Facilitatory and inhibitory neuronal activity within motor cortex can increase or reduce the MEP amplitude. Intracortical facilitation and inhibition can be measured with paired TMS pulses. The first pulse, with an intensity below the threshold for producing an MEP, 'conditions' the motor cortex output mechanism by activating excitatory and inhibitory inputs to the corticospinal neurons. The second, 'test' pulse produces an MEP, which is either reduced (inhibited) or increased in size (facilitated), depending on delay after the conditioning pulse. Normally, an interval of 2-5 ms leads to a smaller MEP (Kujirai et al, 1993), a phenomenon termed short interval intracortical inhibition (SICI). SICI is enhanced by GABAergic drugs (Ziemann et al, 1998), neurosteroids (Smith et al, 2002), and DA agonists (Ziemann et al, 1996a). In contrast, intervals of 8-20 ms lead to a larger MEP (Kujirai et al, 1993) (intracortical facilitation; ICF). Although some evidence suggests that SICI and ICF result from independent processes affecting motor cortex (Orth et al, 2003; Ziemann et al, 1996b), the usual case is that both change together. Thus when a medication increases paired to single pulse MEP amplitude ratios at both short (inhibitory) and long (facilitatory) intervals, this may not indicate two separate effects. It may instead demonstrate the drug affects cortical inhibitory processes measurable to some degree at both short and longer intervals.

Paired pulse TMS studies have consistently demonstrated abnormally reduced SICI in ADHD (Gilbert et al, 2004a, 2005; Moll et al, 2001). However, it remains unclear whether reduced SICI in ADHD represents a lesion, as previously suggested (Moll et al, 2000), or a process compensating for a defect elsewhere. If reduced SICI represents a primary abnormality, it follows that medications that treat ADHD should normalize this response. If reduced SICI indicates a compensatory mechanism, then medications that treat ADHD might augment this response. Although some research suggests that stimulants and DA agonists have heterogeneous behavioral and neurophysiologic effects in normal subjects with differing baseline memory capacities (Kimberg et al, 1997; Mattay et al, 2000), based on prior research showing that stimulants have similar effects in hyperactive and healthy individuals (Rapoport et al, 1980), we expected the direction of ADHD medication-induced changes in SICI to be the same in ADHD and healthy subjects.

Several prior studies have shown that MPH changes SICI and/or ICF (Ilic et al, 2003; Kirschner et al, 2003; Moll et al, 2000, 2003). The effects of ATX on cortical inhibition and excitation have not been studied previously, but based on its beneficial effect in ADHD (Michelson et al, 2001, 2003), we hypothesized that its effect would parallel that of MPH.

Finally, to determine whether our findings are typical of stimulants and selective NE reuptake inhibitors, we abstracted the results of published studies of stimulants and another NE reuptake inhibitor, reboxetine (RBX) (Ratner et al, 2005), on SICI and ICF and generated pooled treatment-effect estimates using meta-analysis methods.

\section{PATIENTS AND METHODS}

\section{Subject Recruitment, Diagnosis, Clinical Assessment}

Nine right-handed adults, free of medical or psychiatric illness, were recruited through advertisement and scheduled for two visits, separated by approximately 1 week. Women were requested not to schedule visits during the premenstrual or menstrual period (Smith et al, 2003). All subjects were examined by a board-certified neurologist (DG). After all procedures were fully explained, all subjects gave written informed consent for the study, which was approved by the Cincinnati Children's Hospital Institutional Review Board.

\section{Study Design and Drug Administration}

This was a randomized, double-blind, crossover study to compare effects of ATX and MPH. Subjects were randomized and assigned by the study pharmacist into crossover group 1 (ATX, then MPH) or 2 (MPH, then ATX). In all, $60 \mathrm{mg}$ ATX and $30 \mathrm{mg}$ MPH were prepared in capsules with identical appearance and similar taste. Subjects and investigators were blinded to the order of treatment assignment throughout the study. The 1-week interval was based on published pharmacokinetic data for single doses of ATX (Witcher et al, 2003) and MPH (Kimko et al, 1999; Shader et al, 1999).

\section{Neurophysiology}

Neurophysiological studies were performed in the TMS laboratory at Cincinnati Children's Hospital Medical Center, using a Magstim $200^{\circledR}$ stimulator (Magstim Co., New York, NY, USA) connected through a Bistim ${ }^{\mathbb{R}}$ module to a $90 \mathrm{~mm}$ circular coil. Subjects were seated in a comfortable dental chair and wore 33-db noise reduction-rated earplugs. The coil was placed with its center near the vertex in the optimal position and orientation for producing a MEP in the right abductor pollicis brevis (APB) muscle. This position was marked with a wax pencil and the coil was clamped to a wall-mounted arm to improve the reproducibility of placement. The EMG was recorded from the right APB with surface electrodes, amplified, and filtered (100/ $1000 \mathrm{~Hz}$ ) (Coulbourn Instruments, Allentown, PA) before being digitized at $2 \mathrm{kHz}$ and stored for analysis using Signal ${ }^{\circledR}$ software and a Micro1401 interface (Cambridge Electronic Design, Cambridge, UK). 
In order to establish intensities for single and paired pulse studies, the resting MEP threshold (RMT) and active MEP threshold (AMT) were measured, using a method similar to that described elsewhere (Mills and Nithi, 1997), by setting the stimulator to $20 \%$ of maximum stimulator output and increasing the intensity by $10 \%$ increments until a MEP was obtained. The intensity was then decreased in increments of $1 \%$ of maximum stimulator output until five of 10 pulses elicited MEPS of $50 \mu \mathrm{V}$. The active MEP threshold (AMT) was determined while the subject contracted the APB with auditory feedback to maintain a constant, moderate level of EMG. The stimulator output was decreased in increments of $1 \%$ from the RMT intensity until the point at which 10 rectified, averaged stimuli failed to show a MEP above background.

SICI and ICF were measured with the APB at rest, according to established paradigms (Kujirai et al, 1993; Ziemann et al, 1997a). The test pulse was set at an intensity that consistently produced a $0.5-1.5 \mathrm{mV}$ MEP when delivered alone. SICI was measured with a (1\% below AMT) conditioning pulse $3 \mathrm{~ms}$ before the test pulse. ICF was measured with the conditioning pulse $10 \mathrm{~ms}$ before the test pulse. In all, 20 trials were performed with paired pulses at each of these intervals and with the test stimulus alone. The trial types ( 3 and $10 \mathrm{~ms}$, test alone) were randomly intermixed and the time between trials was varied randomly by $\leqslant 10 \%$ around a mean of $6 \mathrm{~s}$. The EMG traces were inspected visually offline and any showing voluntary activation of the target muscle were excluded from the analysis. SICI and ICF were expressed as the ratios of the mean MEP amplitude produced by the pairs at each interval to the mean MEP amplitude produced by the test pulse delivered alone.

After baseline TMS testing, subjects were administered study medication and all measurements were repeated, beginning $90 \mathrm{~min}$ later, consistent with expected peak serum drug levels (Swanson and Volkow, 2003; Witcher et al, 2003). Each TMS session took approximately $30 \mathrm{~min}$.

A review of systems, and testing of strength, reflexes, mood, mental status, verbal fluency, and finger-tapping frequency were obtained before and after TMS, and subjects were contacted by phone the following day and questioned regarding adverse effects.

\section{Statistical Analysis}

All analyses were performed with $S A S^{\mathrm{R}}$ version 8.02 (The SAS Institute Inc., Cary, NC, USA).

Exploratory analyses. The distributions of the continuous measures (RMT, AMT, SICI, ICF) were assessed visually for normality. Dispersion of individual trial MEPs was assessed visually, and ratios of both means and medians of individual subject data were calculated. Means and confidence intervals were calculated for raw data.

Regression analyses. SICI, ICF, RMT, and AMT were subjected to a mixed model, repeated measures analysis of variance using PROC MIXED. First, using contrasts, we tested whether baseline measures differed from visit 1 to 2 . Next, the effects of ORDER and TREATMENT were compared, and estimates of parameter means and con- fidence intervals after ATX vs MPH were generated. Final estimates of ATX $v s$ MPH treatment effects were compared after adjusting for each subject's baseline, day-of-treatment measures.

Meta-analysis. MEDLINE literature search in English from 1997 to 2004 was conducted for 'TMS' AND DA OR NE, as well as for classes (eg psychostimulants) and individual names (eg MPH) of drugs. Reference lists were also searched by hand. To be included, studies had to involve healthy adults receiving stimulants or selective NE reuptake inhibitors. Effect sizes were calculated using a mean difference postdrug minus predrug (or postdrug minus postplacebo). The effect of interest for both SICI and ICF was the conditioned to single pulse ratio. Absolute effects were not compared directly across studies because of differences in conditioning pulse intensities and coil types. Target muscles for all studies had to be an intrinsic hand muscle at rest. When possible, from published tables or figures, only the $3 \mathrm{~ms}$ interstimulus interval (ISI) was used for SICI comparisons and the $10 \mathrm{~ms}$ ISI for ICF comparisons. SD were from the predrug measures. The Comprehensive Meta-Analysis Program (Biostat ${ }^{\mathrm{TM}}$ Englewood, NJ) was used to generate meta-analysis estimates and figures separately for stimulants and NE reuptake inhibitors for SICI and ICF. Individual and pooled treatment effects were reported graphically, but $p$-values were not computed for pooled comparisons due to dose differences between studies.

\section{RESULTS}

\section{Demographics, Adverse Events, Dropouts}

Nine individuals (four women; age 19-35 years, mean age $=24 \pm 5$ ) participated. No events during this trial required breaking the code, which was kept by the study pharmacy. All subjects attended both visits, but in one subject, technical difficulties invalidated the data from one session. In addition, one subject was nauseated and vomited during one post-ATX session. The post-treatment data from that visit were also excluded. Thus data from 34 sessions were analyzed.

Seven of nine subjects experienced one or more side effects at the visit for ATX $(n=6)$ and/or MPH $(n=4)$. Reported side effects after ATX and TMS were: numbness/ tingling (two), weakness (one), loss of appetite (one), tiredness (two), scalp itching (one), nausea (three), and vomiting (one). Reported side effects after MPH and TMS were: headache (two), scalp pain (two), numbness/tingling (one), weakness (one), tiredness (one), nausea (one), hyperactivity (one), and increased energy (one). All side effects were mild and transient, except for one subject with moderate nausea, then vomiting, followed by resolution of nausea.

\section{Neurophysiologic Measures}

Observed means and 95\% confidence intervals for SICI, ICF, RMT, and AMT are in Table 1 . The mean and \pm one SE SICI, and ICF for the baselines and post-ATX and -MPH are shown in Figures 1 and 2. 
Table I Effects of MPH and ATX on Motor Cortex Inhibition at $3 \mathrm{~ms}$ (SICl) and $10 \mathrm{~ms}$ (ICF) Intervals

\begin{tabular}{|c|c|c|c|c|}
\hline TMS measure & $\begin{array}{c}\text { Pre-ATX } \\
\text { mean }(95 \% \mathrm{Cl})\end{array}$ & $\begin{array}{c}\text { Post-ATX } \\
\text { mean }(95 \% \mathrm{Cl})\end{array}$ & $\begin{array}{c}\text { Pre-MPH } \\
\text { mean }(95 \% \mathrm{Cl})\end{array}$ & $\begin{array}{c}\text { Post-MPH } \\
\text { mean }(95 \% \mathrm{Cl})\end{array}$ \\
\hline MEP amplitude ratios after $10 \mathrm{~ms}$ paired-pulse TMS & $1.23(1.13-1.33)$ & $1.37(1.04-1.9)$ & $1.16(0.91-1.41)$ & $1.23(1.03-1.44)$ \\
\hline Resting motor threshold & $47(42-52)$ & $48(40-55)$ & $49(43-56)$ & $49(42-56)$ \\
\hline Active motor threshold & $34(29-39)$ & $34(29-40)$ & $37(33-40)$ & $35(30-40)$ \\
\hline
\end{tabular}

Means and 95\% confidence intervals (Cl) of MEP amplitude ratios pre- and post-MPH and ATX. Motor thresholds expressed as a percent of maximum stimulator intensity. $\mathrm{ATX}=$ atomoxetine; $\mathrm{MEP}=$ motor-evoked potential; $\mathrm{MPH}=$ methylphenidate; $\mathrm{TMS}=$ transcranial magnetic stimulation.

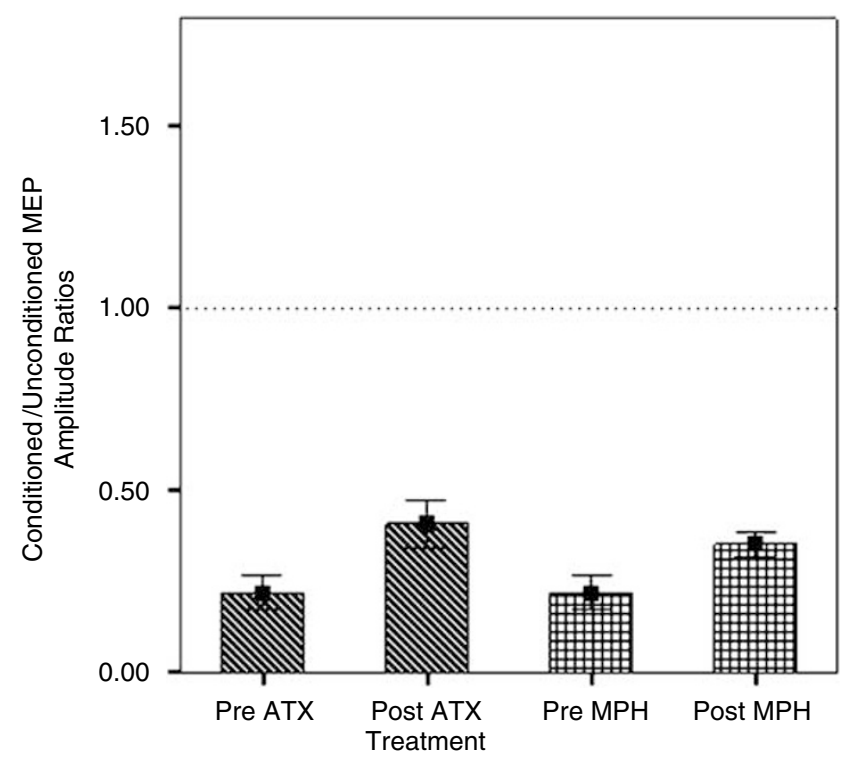

Figure I Treatment with ATX and MPH significantly increased the MEP amplitude ratios at the inhibitory, 3 ms paired pulse interval. Short interval cortical inhibition before and after atomoxetine (ATX) and methylphenidate $(\mathrm{MPH})$.

Baseline, order effects. There were no significant differences in any pretreatment neurophysiological measures at visit one $v s$ visit two. Although the pre-MPH ICF was lower than the pre-ATX ICF, this difference was not significant $\left(t_{7}=-0.47 ; p=0.65\right)$. There was no significant effect of treatment order.

Treatment effects. Drug treatment increased paired to single pulse-evoked MEP amplitude ratios at both short $\left(\mathrm{F}_{2,7}=54.2, p<0.0001\right)$. and long $\left(\mathrm{F}_{2,7}=7.00, p=0.02\right)$ intervals (see Table 1, Figures 1 and 2).

There were no treatment-induced changes in RMT or AMT.

Comparison of ATX vs MPH effects after adjustment for baselines. After adjustment for pretreatment measures, there was a trend toward a greater post-ATX decrease in SICI, but the differences after MPH vs ATX $\left(\mathrm{F}_{1,7}=3.98\right.$, $p=0.086)$ were not significant. Also, differences in increases in ICF after MPH $v s$ ATX $\left(\mathrm{F}_{1,7}=0.25, p=0.63\right)$ were not significant.

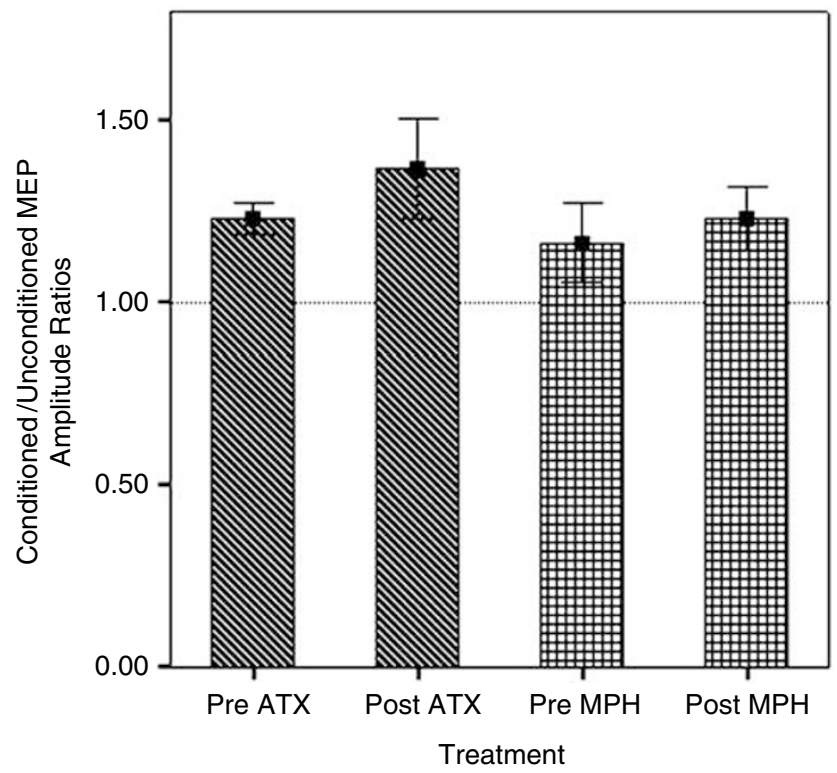

Figure 2 Treatment with ATX and MPH significantly increased the MEP amplitude ratios at the facilitatory, 10 ms paired pulse interval. Intracortical facilitation before and after atomoxetine and methylphenidate.

Meta-analysis results. Table 2 summarizes studies of dopaminergic and noradrenergic medications and their effects on neurophysiologic measures. Tables 3 and 4 provide estimates of effect sizes for the present study, three additional studies of MPH, and two studies of RBX, a selective NE reuptake inhibitor similar to ATX. Although the summary estimate results cannot be considered precise, there appears in general to be a decrease in SICI and an increase in ICF after either NE reuptake inhibitors or stimulants in healthy adults.

\section{DISCUSSION}

Our results show that MPH and ATX produce similar physiologic effects in cortex of healthy adults. Both ADHD drugs significantly increased paired pulse to single pulse MEP amplitude ratios, thereby reducing SICI and increasing ICF. These shared effects occur despite different pharmacologic actions in striatum (Bymaster et al, 2002), indicating that both may affect a key cortical target for ADHD treatment. Synthesis of our results and other published data 
Table 2 Effects of Selective Norepinephrine Reuptake Inhibitors, Stimulants, and Dopamine Agonists on Motor Cortex Inhibition at Inhibitory and Facilitatory Interstimulus Intervals

Effect on paired/

single pulse MEP

amplitude ratios

\section{Medication and dose $N \quad 2-5 \mathrm{~ms} \quad 7-20 \mathrm{~ms}$ Citation}

Selective norepinephrine reuptake inhibitors

Atomoxetine $60 \mathrm{mg}$

Reboxetine $8 \mathrm{mg}$

Reboxetine $8 \mathrm{mg}$

Reboxetine $4 \mathrm{mg}$
$+$

$8+$

5 NS

5 NS

NS

\section{Stimulants}

D-amphetamine $10 \mathrm{mg}$

Methylphenidate $10 \mathrm{mg}$

Methylphenidate $30 \mathrm{mg}$

Methylphenidate $40 \mathrm{mg}$

Methylphenidate $40 \mathrm{mg}$

9
12
9
12
8

NS

NS

$+$

$-$

$+$

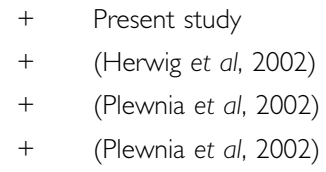
$+\quad$ (Boroojerdi et al, 200I)
$+\quad$ (Moll et al, 2003)
NS Present study
$+\quad$ (Kirschner et al, 2003)
$+\quad$ (llic et al, 2003)

DA agonists

Pergolide 0.125 mg $\quad 5 \quad$ - $\quad$ NS (Ziemann et al, 1996a)

Bromocryptine $5 \mathrm{mg} \quad 5 \quad-\quad \quad$ NS (Ziemann et al, 1997b)

MEP = motor-evoked potential; NS = not significant; '-' = decreased conditioned/unconditioned MEP amplitude ratios; '+' = increased conditioned/ unconditioned MEP amplitude ratios.

Note that when a drug increases ('+') the MEP amplitude ratio at 2-5 ms intervals, this indicates decreased SICl; but ' + ' at 7-20 ms intervals indicates increased ICF. Similarly, when a drug decreases ('-') the MEP amplitude ratio at 2-5 ms intervals, this indicates increased $\mathrm{SICl}$; but '-' at $7-20 \mathrm{~ms}$ intervals indicates decreased ICF.

demonstrates that the effects of catecholaminergic drugs on SICI and ICF are basically consistent in healthy individuals (Tables 3 and 4). Thus SICI, and possibly ICF, may be considered markers of both ADHD symptoms (Gilbert et al, 2004a; Moll et al, 2001) and treatment effects in healthy individuals.

Although we could not measure the response of prefrontal cortex directly, the noradrenergic and dopaminergic systems involved in the genesis and treatment of ADHD are also present in motor cortex. For example, the dopaminergic projection from the ventral tegmental area (Lindvall et al, 1974) terminates on pyramidal cells and interneurons (Sesack et al, 1995) and likely regulates their excitability. Studies in cats (Huda et al, 2001) and rodents (Awenowicz and Porter, 2002) have demonstrated reduced excitability in motor neurons, which produce the MEP to TMS, after application of DA. A recent study in monkey prefrontal cortex showed that DA decreases horizontal excitatory transmission in cortical layer 5 by a $\mathrm{D} 1$ receptormediated mechanism (Gao et al, 2001). Such horizontal excitatory connections in the motor cortex are likely involved in the amplification of excitatory signals that results in the MEP after TMS.
The mechanism of the TMS-paired pulse inhibitory effect in cortex has not been studied in animals, but may involve the output of relevant, drug-responsive populations of inhibitory interneurons found in both frontal and prefrontal cortex. Ultrastructural studies suggest that, in primates, DA terminals occur on GABAergic interneurons closely associated with pyramidal (output) cells (Sesack et al, 1998). Studies of the effects of DA on cortical inhibitory interneurons (Gao and Goldman-Rakic, 2003) show both inhibitory (in nonfast spiking interneurons) and facilitatory (in fast spiking interneurons) effects. Interestingly, DA appears to enhance inhibition of pyramidal neurons by peridendritic interneurons that are thought to modulate the sensitivity of the pyramidal neurons to excitatory synaptic inputs, such as those that might result in TMS-induced firing. In addition, D4 receptor function may be involved in fine-tuning inhibitory function (Gao and Goldman-Rakic, 2003; LaHoste et al, 1996; Mrzljak et al, 1996; Swanson et al, 1998). Both NE and DA can act as D4 receptor agonists (Lanau et al, 1997; Newman-Tancredi et al, 1997). Therefore, the substrate appears to exist in both motor and prefrontal cortex for ADHD drugs to act, and SICI in motor cortex may provide a surrogate measure for prefrontal effects.

If, as our findings and the pooled effects in Table 3 suggest, anti-ADHD drugs reduce SICI, then reduced SICI in ADHD may represent a compensatory process rather than a primary abnormality. However, it is necessary to consider other studies which do not seem to support this idea and several possible causes for variation in study results.

First, the only published TMS study of MPH in children with ADHD showed that $10 \mathrm{mg}$ MPH increased SICI (Moll et al, 2000). The authors interpreted this as showing that MPH 'normalizes' SICI in ADHD children. When, subsequently, these authors found in healthy adults that $10 \mathrm{mg}$ MPH increased ICF but failed to increase SICI (Moll et al, 2003), they suggested that MPH exerts opposite effects in healthy adults compared to ADHD children. However, their assessment of the relationship between drug-induced changes in SICI and diagnosis of ADHD is confounded by age. That is, one cannot determine whether the differences in MPH induced changes in SICI are due to diagnosis (ADHD yes/no), as they claim, or to age (child, adult).

A second issue in comparing these studies is dosage. Absence of a statistically significant effect of $10 \mathrm{mg} \mathrm{MPH}$ in adults (Moll et al, 2003) may be because the dose was subtherapeutic. Alternatively, it is possible that at lower doses, MPH may increase SICI, similar to the effect of DA agonists (see Table 2) (Ziemann et al, 1996a, 1997b), while at higher doses, MPH may reduce SICI, as we found, perhaps via NE-mediated effects. Dose-ranging studies in ADHD affected and unaffected individuals, and comparisons with more receptor-specific agents, may be needed to clarify this.

Finally, three additional factors are worth mentioning. Variations in paired pulse techniques may contribute to different estimates of drug treatment on SICI and ICF. Study design and choice of statistical analyses may also have played a role. In this regard, we believe the crossover design with pre- and postdose TMS and baseline-adjusted repeated measures statistical analysis that we used is very robust. 
Table 3 Effects of Stimulants and Norepinephrine Reuptake Inhibitors on SICl

\begin{tabular}{|c|c|c|c|c|c|c|c|c|c|c|c|}
\hline & & & Met: & analysis of $A D$ & ID di & Ig effect & SICI & & & & \\
\hline & SNRI & Plewnia, 2002 & RBX & $\mathrm{SICl}$ & 5 & 0.442 & & & & & \\
\hline & SNRI & Herwig, 2002 & RBX & $\mathrm{SICl}$ & 8 & 1.504 & & & & & \\
\hline \multirow[t]{5}{*}{ Fixed } & SNRI (3) & & & & 22 & 1.168 & & & & & \\
\hline & Stimulant & Present study & $\mathrm{MPH}$ & $\mathrm{SICl}$ & 9 & 0.952 & & & & & \\
\hline & Stimulant & Moll, 2003 & $\mathrm{MPH}$ & $\mathrm{SICl}$ & 12 & 0.146 & & & & & \\
\hline & Stimulant & Kirschner, 2003 & $\mathrm{MPH}$ & $\mathrm{SICl}$ & 12 & -0.453 & & & & & \\
\hline & Stimulant & Ilic, 2003 & $\mathrm{MPH}$ & $\mathrm{SICl}$ & 8 & 1.418 & & & & & \\
\hline Fixed & Stimulant (4) & & & & 41 & 0.333 & & & & & \\
\hline
\end{tabular}

Table 4 Effects of Stimulants and Norepinephrine Reuptake Inhibitors on Conditioned/Unconditioned MEP Amplitude Ratios-ICF

\begin{tabular}{|c|c|c|c|c|c|c|c|c|c|c|c|}
\hline \multicolumn{12}{|c|}{ Meta-analysis of ADHD drug effects on ICF } \\
\hline & SNRI & Plewnia, 2002 & RBX & ICF & 5 & 0.474 & & & & & \\
\hline & SNRI & Herwig, 2002 & RBX & ICF & 8 & 1.306 & & & & - & \\
\hline \multirow[t]{5}{*}{ Fixed } & SNRI (3) & & & & 22 & 1.024 & & & & & \\
\hline & Stimulant & Present study & $\mathrm{MPH}$ & ICF & 9 & 0.208 & & & & & \\
\hline & Stimulant & Moll, 2003 & $\mathrm{MPH}$ & ICF & 12 & 0.761 & & & & & \\
\hline & Stimulant & Kirschner, 2003 & $\mathrm{MPH}$ & ICF & 12 & 0.193 & & & & & \\
\hline & Stimulant & Ilic, 2003 & $\mathrm{MPH}$ & ICF & 8 & 0.640 & & & & & \\
\hline Fixed & Stimulant (4) & & & & 41 & $0.44 I$ & & & & & \\
\hline
\end{tabular}

Finally, there may be other unmeasured differences in the cohorts of normal individuals involved in these different studies, perhaps involving working memory capacity, such that dopaminergic agents may produce heterogeneous drug-induced changes in cortical physiology (Kimberg et al, 1997; Mattay et al, 2000).

Our study was limited by the lack of a placebo group. However, we doubt this confounded our results, because prior placebo-controlled studies have not shown significant changes in these measures due to placebo or time (Reis et al, 2002; Tergau et al, 2003). Moreover, time did not influence thresholds (see Table 1) and the crossover design means that we had two opportunities to observe prepost time effects, one on each medication, in each subject, and found no evidence of such effects.
A further limitation is that we did not measure drug levels. One prior study failed to find a significant correlation between MPH plasma levels and measures of cortical excitability (Kirschner et al, 2003). However, we cannot exclude the possibility that regression modeling with drug levels would have increased the precision of the drug-effect estimate. In addition, it should be pointed out that both MPH and ATX are given chronically in ADHD therapy, and all studies to date, including this one, are single dose studies. MPH has first-dose behavioral effects, but ATX may take two to 4 weeks to achieve efficacy. Thus, the cortical effects of continuous ATX therapy await further study.

In conclusion, the results of this study and others in our meta-analysis suggest that TMS-evoked motor cortex inhibition is a consistent surrogate of the ADHD drug 
treatment responses, as well as ADHD symptoms (Gilbert et al, 2004a, 2005; Moll et al, 2001).

\section{ACKNOWLEDGEMENTS}

We gratefully acknowledge the time devoted to this study by the adult volunteers who participated, and technical assistance by Kevin Ferguson. This research was supported by an independent, investigator-initiated grant from Lilly Research Laboratories, a Division of Eli Lilly and Company (Indianapolis, IN); and by National Institute of Neurological Disorders and Stroke K23 NS41920. This work was presented in abstract form at the 57th American Academy of Neurology Annual Meeting, Miami, FL, April 13, 2005.

\section{REFERENCES}

Awenowicz PW, Porter LL (2002). Local application of dopamine inhibits pyramidal tract neuron activity in the rodent motor cortex. J Neurophysiol 88: 3439-3451.

Boroojerdi B, Battaglia F, Muellbacher W, Cohen LG (2001). Mechanisms influencing stimulus-response properties of the human corticospinal system. Clin Neurophysiol 112: 931-937.

Buchmann J, Wolters A, Haessler F, Bohne S, Nordbeck R, Kunesch E (2003). Disturbed transcallosally mediated motor inhibition in children with attention deficit hyperactivity disorder (ADHD). Clin Neurophysiol 114: 2036-2042.

Bymaster FP, Katner JS, Nelson DL, Hemrick-Luecke SK, Threlkeld PG, Heiligenstein JH et al (2002). Atomoxetine increases extracellular levels of norepinephrine and dopamine in prefrontal cortex of rat: a potential mechanism for efficacy in attention deficit/hyperactivity disorder. Neuropsychopharmacology 27: 699-711.

Cracco RQ, Cracco JB, Maccabee PJ, Amassian VE (1999). Cerebral function revealed by transcranial magnetic stimulation. $J$ Neurosci Methods 86: 209-219.

Daskalakis ZJ, Christensen BK, Fitzgerald PB, Chen R (2002). Transcranial magnetic stimulation: a new investigational and treatment tool in psychiatry. J Neuropsychiatry Clin Neurosci 14: 406-415.

Gao WJ, Goldman-Rakic PS (2003). Selective modulation of excitatory and inhibitory microcircuits by dopamine. Proc Natl Acad Sci USA 100: 2836-2841.

Gao WJ, Krimer LS, Goldman-Rakic PS (2001). Presynaptic regulation of recurrent excitation by D1 receptors in prefrontal circuits. Proc Natl Acad Sci USA 98: 295-300.

Garvey MA, Kaczynski KJ, Becker DA, Bartko JJ (2001). Subjective reactions of children to single-pulse transcranial magnetic stimulation. J Child Neurol 16: 891-894.

Gilbert DL, Bansal AS, Sethuraman G, Sallee FR, Zhang J, Lipps T et al (2004a). Association of cortical disinhibition with tic, ADHD, and OCD severity in Tourette syndrome. Mov Disord 19: 416-425.

Gilbert DL, Garvey MA, Bansal AS, Lipps T, Zhang J, Wassermann EM (2004b). Should transcranial magnetic stimulation research in children be considered minimal risk? Clin Neurophysiol 115: 1730-1739.

Gilbert DL, Sallee FR, Zhang J, Lipps TD, Wassermann EM (2005). TMS-evoked cortical inhibition: a consistent marker of ADHD scores in Tourette Syndrome. Biol Psychiatr 57: 1597-1600.

Herwig U, Brauer K, Connemann B, Spitzer M, Schonfeldt-Lecuona C (2002). Intracortical excitability is modulated by a norepinephrine-reuptake inhibitor as measured with paired-pulse transcranial magnetic stimulation. Psychopharmacology (Berl) 164: 228-232.
Huda K, Salunga TL, Matsunami K (2001). Dopaminergic inhibition of excitatory inputs onto pyramidal tract neurons in cat motor cortex. Neurosci Lett 307: 175-178.

Ilic TV, Korchounov A, Ziemann U (2003). Methylphenidate facilitates and disinhibits the motor cortex in intact humans. Neuroreport 14: 773-776.

Kimberg DY, D’Esposito M, Farah MJ (1997). Effects of bromocriptine on human subjects depend on working memory capacity. Neuroreport 8: 3581-3585.

Kimko HC, Cross JT, Abernethy DR (1999). Pharmacokinetics and clinical effectiveness of methylphenidate. Clin Pharmacokinet 37: 457-470.

Kirschner J, Moll GH, Fietzek UM, Heinrich H, Mall V, Berweck S, et al (2003). Methylphenidate enhances both intracortical inhibition and facilitation in healthy adults. Pharmacopsychiatr 36: 79-82.

Kujirai T, Caramia MD, Rothwell JC, Day BL, Thompson PD, Ferbert A et al (1993). Corticocortical inhibition in human motor cortex. J Physiol 471: 501-519.:501-519.

LaHoste GJ, Swanson JM, Wigal SB, Glabe C, Wigal T, King N et al (1996). Dopamine D4 receptor gene polymorphism is associated with attention deficit hyperactivity disorder [see comment]. Mol Psychiatr 1: 121-124.

Lanau F, Zenner MT, Civelli O, Hartman DS (1997). Epinephrine and norepinephrine act as potent agonists at the recombinant human dopamine D4 receptor. J Neurochem 68: 804-812.

Lindvall O, Bjorklund A, Moore RY, Stenevi U (1974). Mesencephalic dopamine neurons projecting to neocortex. Brain Res 81: 325-331.

Mattay VS, Callicott JH, Bertolino A, Heaton I, Frank JA, Coppola $\mathrm{R}$ et al (2000). Effects of dextroamphetamine on cognitive performance and cortical activation. Neuroimage 12: 268-275.

Michelson D, Adler L, Spencer T, Reimherr FW, West SA, Allen AJ et al (2003). Atomoxetine in adults with ADHD: two randomized, placebo-controlled studies. Biol Psychiatr 53: 112-120.

Michelson D, Faries D, Wernicke J, Kelsey D, Kendrick K, Sallee FR et al (2001). Atomoxetine in the treatment of children and adolescents with attention-deficit/hyperactivity disorder: a randomized, placebo-controlled, dose-response study. Pediatrics 108: E83.

Mills KR, Nithi KA (1997). Corticomotor threshold to magnetic stimulation: normal values and repeatability. Muscle Nerve 20: 570-576.

Moll GH, Heinrich H, Rothenberger A (2003). Methylphenidate and intracortical excitability: opposite effects in healthy subjects and attention-deficit hyperactivity disorder. Acta Psychiatr Scand 107: 69-72.

Moll GH, Heinrich H, Trott G, Wirth S, Bock N, Rothenberger A (2001). Children with comorbid attention-deficit-hyperactivity disorder and tic disorder: evidence for additive inhibitory deficits within the motor system. Ann Neurol 49: 393-396.

Moll GH, Heinrich H, Trott G, Wirth S, Rothenberger A (2000). Deficient intracortical inhibition in drug-naive children with attention-deficit hyperactivity disorder is enhanced by methylphenidate. Neurosci Lett 284: 121-125.

Mrzljak L, Bergson C, Pappy M, Huff R, Levenson R, GoldmanRakic PS (1996). Localization of dopamine D4 receptors in GABAergic neurons of the primate brain. Nature 381: 245-248. Nakamura H, Kitagawa H, Kawaguchi Y, Tsuji H (1997). Intracortical facilitation and inhibition after transcranial magnetic stimulation in conscious humans. J Physiol (Lond) 498: 817-823.

Newman-Tancredi A, Audinot-Bouchez V, Gobert A, Millan MJ (1997). Noradrenaline and adrenaline are high affinity agonists at dopamine D4 receptors. Eur J Pharmacol 319: 379-383.

Orth M, Snijders AH, Rothwell JC, Papathanasiou I, Filipovi AS, Whurr R et al (2003). The variability of intracortical inhibition and facilitation. Clin Neurophysiol 114: 2362-2369. 
Patton HD, Amassian VE (1954). Single and multiple unit analysis of cortical stage of pyramidal tract activation. J Neurophysiol 17: 345-363.

Plewnia C, Hoppe J, Hiemke C, Bartels M, Cohen LG, Gerloff C (2002). Enhancement of human cortico-motoneuronal excitability by the selective norepinephrine reuptake inhibitor reboxetine. Neurosci Lett 330: 231-234.

Rapoport JL, Buchsbaum MS, Weingartner H, Zahn TP, Ludlow C, Mikkelsen EJ (1980). Dextroamphetamine. Its cognitive and behavioral effects in normal and hyperactive boys and normal men. Arch Gen Psychiatr 37: 933-943.

Ratner S, Laor N, Bronstein Y, Weizman A, Toren P (2005). Sixweek open-label reboxetine treatment in children and adolescents with attention-deficit/hyperactivity disorder. J Am Acad Child Adolesc Psychiatr 44: 428-433.

Reis J, Tergau F, Hamer HM, Muller HH, Knake S, Fritsch B et al (2002). Topiramate selectively decreases intracortical excitability in human motor cortex. Epilepsia 43: 1149-1156.

Sesack SR, Hawrylak VA, Melchitzky DS, Lewis DA (1998). Dopamine innervation of a subclass of local circuit neurons in monkey prefrontal cortex: ultrastructural analysis of tyrosine hydroxylase and parvalbumin immunoreactive structures. Cereb Cortex 8: 614-622.

Sesack SR, Snyder CL, Lewis DA (1995). Axon terminals immunolabeled for dopamine or tyrosine hydroxylase synapse on GABA-immunoreactive dendrites in rat and monkey cortex. J Comp Neurol 363: 264-280.

Shader RI, Harmatz JS, Oesterheld JR, Parmelee DX, Sallee FR, Greenblatt DJ (1999). Population pharmacokinetics of methylphenidate in children with attention-deficit hyperactivity disorder. J Clin Pharmacol 39: 775-785.

Smith MJ, Adams LF, Schmidt PJ, Rubinow DR, Wassermann EM (2002). Ovarian hormone effects on human cortical excitability. Ann Neurol 51: 599-603.

Smith MJ, Adams LF, Schmidt PJ, Rubinow DR, Wassermann EM (2003). Abnormal luteal phase excitability of the motor cortex in women with premenstrual syndrome. Biol Psychiatr 54: 757-762.

Swanson JM, Sunohara GA, Kennedy JL, Regino R, Fineberg E, Wigal T et al (1998). Association of the dopamine receptor D4 (DRD4) gene with a refined phenotype of attention deficit hyperactivity disorder (ADHD): a family-based approach. $\mathrm{Mol}$ Psychiatr 3: 38-41.
Swanson JM, Volkow ND (2003). Serum and brain concentrations of methylphenidate: implications for use and abuse. Neurosci Biobehav Rev 27: 615-621.

Tergau F, Wischer S, Somal HS, Nitsche MA, Joe Mercer A, Paulus W et al (2003). Relationship between lamotrigine oral dose, serum level and its inhibitory effect on CNS: insights from transcranial magnetic stimulation. Epilepsy Res 56: 67-77.

Ucles P, Lorente S, Rosa F (1996). Neurophysiological methods testing the psychoneural basis of attention deficit hyperactivity disorder. Childs Nerv Syst 12: 215-217.

Volkow ND, Wang GJ, Fowler JS, Gatley SJ, Logan J, Ding YS et al (1998). Dopamine transporter occupancies in the human brain induced by therapeutic doses of oral methylphenidate. Am J Psychiatr 155: 1325-1331.

Witcher JW, Long A, Smith B, Sauer JM, Heilgenstein J, Wilens T et al (2003). Atomoxetine pharmacokinetics in children and adolescents with attention deficit hyperactivity disorder. J Child Adolesc Psychopharmacol 13: 53-63.

Zerbe RL, Rowe H, Enas GG, Wong D, Farid N, Lemberger L (1985). Clinical pharmacology of tomoxetine, a potential antidepressant. J Pharmacol Exp Therap 232: 139-143.

Ziemann U (2004). TMS and drugs. Clin Neurophysiol 115: $1717-1729$.

Ziemann U, Bruns D, Paulus W (1996a). Enhancement of human motor cortex inhibition by the dopamine receptor agonist pergolide: evidence from transcranial magnetic stimulation. Neurosci Lett 208: 187-190.

Ziemann U, Paulus W, Rothenberger A (1997a). Decreased motor inhibition in Tourette's Disorder: evidence from transcranial magnetic stimulation. Am J Psychiatr 154: 1277-1284.

Ziemann U, Rothwell JC, Ridding MC (1996b). Interaction between intracortical inhibition and facilitation in human motor cortex. J Physiol (Lond) 496: 873-881.

Ziemann U, Steinhoff BJ, Tergau F, Paulus W (1998). Transcranial magnetic stimulation: its current role in epilepsy research. Epilepsy Res 30: 11-30.

Ziemann U, Tergau F, Bruns D, Baudewig J, Paulus W (1997b). Changes in human motor cortex excitability induced by dopaminergic and anti-dopaminergic drugs. Electroencephalogr Clin Neurophysiol 105: 430-437. 